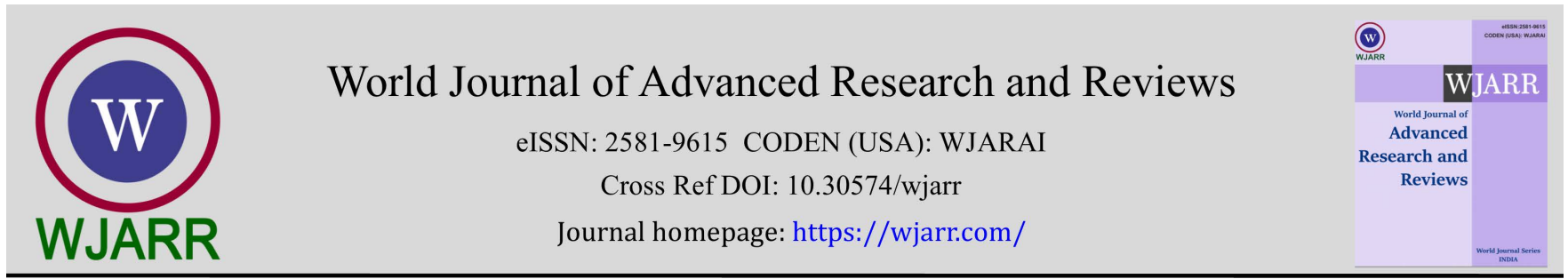

(RESEARCH ARTiCle)

\title{
Effects of phosphorus and iron on biomass production and nutrients partitioning in soybean cultivars under water stress condition
}

\author{
Rotaru Vladimir * and Gusan Ana \\ Institute of Genetics, Physiology and Plant Protection, 20 Padurii str., MD 2002, Chisinau, Republic of Moldova.
}

World Journal of Advanced Research and Reviews, 2021, 12(03), 414-422

Publication history: Received on 07 November 2021; revised on 20 December 2021; accepted on 22 December 2021

Article DOI: https://doi.org/10.30574/wjarr.2021.12.3.0686

\begin{abstract}
A pot experiment was conducted to investigate the effects of $\mathrm{P}$ and Fe application on the biomass production and nutrients partitioning of two soybeans (Glycine max. L. Merr) cultivars grown in carbonated chernoziom (low in Fe and

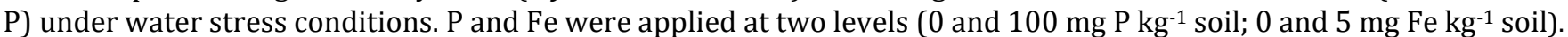
Control plants were grown at 70\% water holding capacity (WHC) while their counterparts were subjected to $35 \%$ WHC water stress at initial flowering stage for two weeks. Considerable variability was observed in leaves, roots dry mass accumulation and nodulation among the soybean cultivars (Zodiac, Licurici) at both P and Fe levels in relation to water regimes. The results showed that drought significantly reduced biomass production irrespective of nutrient supply and its adverse effect was more pronounced at low nutrient supply. Leaf development and nodules growth were the most sensitive to water deficit and insufficient nutrient supply. Adequate P and Fe supply increased dry matter production and nutrient concentrations for soybean cultivars. Phosphorus concentration in plant parts was significantly higher at nil Fe compared with Fe application. Phosphorus application decreased Fe allocation to the leaves. The experimental results demonstrated that there was a positive effect of $\mathrm{P}$ and Fe adequate nutrition on $\mathrm{P}$ use efficiency. Hence, the sufficient phosphorus and iron supply maintained growth at high level, improved $\mathrm{P}$ and Fe status and partially alleviated drought effect on soybean plants.
\end{abstract}

Keywords: Biomass; Phosphorus; Iron; Phosphorus use efficiency; Soybean; Water stress

\section{Introduction}

Plant growth and nutrients distribution in plant parts are influenced by many environmental factors. Among these water stress and inadequate mineral nutrition are the major constraints affecting plant nutrition and productivity [1, 2]. Phosphorus (P) and iron (Fe) deficiencies are widespread nutritional constraints in crops production [3], especially in legumes [4]. Phosphorus deficiency affects a large range of physiological processes namely the nodulation and $\mathrm{N}_{2}$ fixation, and nutrient uptake $[5,6]$. In plants referring to $\mathrm{N}_{2}$ fixation, $\mathrm{P}$ stimulates nodulation and nitrogen fixation more than plant growth [7, 8]. Glycine max L. Merr. plants as relying solely on symbiotic $\mathrm{N}_{2}$ fixation [9] as nitrate feed [10] have a higher internal $P$ requirement for optimum growth and nutrient status. A sufficient $P$ supply increases the wholeplant nitrogen $(\mathrm{N})$ and $\mathrm{P}$ concentrations and growth in many legumes species, especially soybean [9].

Apart from enhancing $\mathrm{N}$ acquisition and dry matter yield on $\mathrm{P}$ deficient soils, $\mathrm{P}$ fertilization may also influence the uptake of micronutrients, especially, of less available forms such as Fe [11,12]. Nitrogenase activity of soybean nodules is strongly related to both $\mathrm{P}$ and Fe supply $[13,14]$. Several studies have shown that $\mathrm{P}$ application, in particular at higher doses, decreases Fe uptake by plants $[15,16]$. Other investigations, however, have revealed no antagonistic interactions between $\mathrm{P}$ and Fe [17]. It is necessary to be mentioned that legume-rhizobium symbiosis is particularly sensitive to Fe

\footnotetext{
* Corresponding author: Rotaru Vladimir

Institute of Genetics, Physiology and Plant Protection, 20 Padurii str., MD 2002, Chisinau, Republic of Moldova. 
deficiency [18]. Iron deficiency can limit survival and multiplication of root nodule bacteria. Further, it can influence host-plant growth as well as nodule development and function.

Nutrient deficiency of soil is frequently accompanied by water deficit [19]. It has been shown that drought may influence the pattern of uptake of mineral elements in plant tissues by affecting root growth and their activity as well as nutrient mobility in soil [20]. Under drought conditions, the availability of P decreases and plant growth is severely hampered by nutrient deficiency under water stress conditions. The major deficit is observed in the transport of nutrients, particularly $\mathrm{P}$, to the roots and on root growth and elongation. It was reported that the nutrient acquisition by plants in drought conditions may have an important role in drought tolerance [20]. Jin et al. [21] reported that the application of $\mathrm{P}$ alleviates drought-stress effects on soybean yields. There is a strong relationship between $\mathrm{P}$ and water supply. For instance, $\mathrm{P}$ improvement has been shown to increase water-use efficiency [18] and drought tolerance [22]. Nevertheless, less is known regarding Fe behavior in relation to $\mathrm{P}$ and water supply. To date the effect of $\mathrm{P}$ and Fe on dry mass partitioning and nutrient acquisition in soybean under water stress has not been elucidated. Literature analysis indicated that these two key nutrients for soybean performance have been studied in normal water conditions and less is known about their interactions under low water supply. This study was undertaken (i) to investigate the effects of $\mathrm{P}$ and Fe supply on plant biomass partitioning and tissue nutrients concentrations in two soybean cultivars under water stress conditions and (ii) to assess the rates of PUE in these cultivars.

\section{Material and methods}

The experiment consisted of carbonated chernoziom soil with low available concentration of $9 \mathrm{mg} \mathrm{P} \mathrm{kg}^{-1}$ and $5.4 \mathrm{mg}$ Fe $\mathrm{mg} \mathrm{kg}^{-1}$ soil and $\mathrm{pH}$ of soil was 7,8. Two soybean (Glycine max. L) cultivars namely Licurici and Zodiac were tested. These cultivars differ in their sensitivity to drought. Four nutrient treatments and two water regimes effects on soybean were investigated. Inoculation with Bradyrhizobium japonicum strain was applied to all plants. All treatments were replicated four times and their abbreviated names are listed in Table 1 . A basal dose of $50 \mathrm{mg} \mathrm{N}$ per $\mathrm{kg}$ soil in the form of (Ca $\left(\mathrm{NO}_{3}\right)_{2} \mathrm{XH}_{2} \mathrm{O}$ was applied to all the pots. The quantity of $\mathrm{P}\left(\mathrm{KH}_{2} \mathrm{PO}_{4}\right)$ for soil experiment was $100 \mathrm{mg} \mathrm{Pg}^{-1} \mathrm{soil}$ as sufficient supply (denoted as P100) and without $\mathrm{P}$ application as insufficient supply (denoted as P0). Additional potassium $(\mathrm{K})$ applied through $\mathrm{KH}_{2} \mathrm{PO}_{4}$ in $\mathrm{P}$ treatments were compensated by applying $\mathrm{KCl}$ in other treatments. Iron was applied as Fe-EDTA at $5 \mathrm{mg} \mathrm{Fe} \mathrm{kg}^{-1}$ soil as sufficient supply (denoted as Fe5) and without micronutrient application (denoted as $\mathrm{Fe} 0$ ). All nutrient solutions were thoroughly mixed in the soil before potting. Until flowering, the plants received adequate water supply-70\% water holding capacity (WHC). At the onset of flower buds the two soil moisture treatments were performed by maintaining pots at normal level of moisture (control) and other set of plants was subjected to $35 \%$ WHC as water stress for 2 weeks.

Both control and water stressed plants were harvested at the end of the flowering stage. Roots and nodules were washed under running water and the number of nodules per plant was counted and recorded. The leaves, stems, roots and nodules were dried separately in an oven with air circulation at $75^{\circ} \mathrm{C}$ for 48 hours and the dry weights were recorded. Total phosphorus content was determined by the colorimetric molybdenum-blue method [23]. Iron was measured in plant tissue samples which were ashed overnight at $500^{\circ} \mathrm{C}$ in a furnace. Fe analysis was conducted by atomic absorption spectrophotometry. Phosphorus use efficiency (PUE) was calculated as biomass production per unit of P uptake. The experimental data were analyzed by ANOVA and means were compared by Least Significant Difference Test (LSD) at $\mathrm{P} \leq 0.05$.

\section{Results}

Soybean cultivars and tested abiotic factors had significant $(\mathrm{P} \leq 0.05)$ interactive effects on leaves, roots growth and nodulation as well as on plant dry matter production (Table 1 and 2).

Differences in partitioning of biomass caused by nutrient application and water supply indicated the existence of genetic differences for responsiveness to $\mathrm{P}$ and Fe nutrition conditions. The lowest biomass production was registered in treatments with both nutrients deficiency. Adequate P and Fe supply increased leaf growth of plants irrespective of water regimes. Control (well-watered) plants produced more assimilates than plants subjected to drought stress. Dry matter distribution of water stressed plants was highest in leaves and stems and lowest in nodules. The experimental results showed that the normal moisture level increased the shoot dry weight evidently, but its effect on roots was less pronounced. 
Table 1 Biomass production and partitioning of Zodiac cultivar at low and adequate supply of $\mathrm{P}$ and Fe grown under well-watered (70\% WHC) and drought (35\% WHC), g plant-1 DW

\begin{tabular}{|l|l|l|l|l|l|l|l|l|l|c|}
\hline \multirow{2}{*}{ Treatments } & \multicolumn{2}{l}{ Leaves } & \multicolumn{2}{l|}{ Stems } & \multicolumn{2}{l|}{ Roots } & \multicolumn{2}{l|}{ Nodules } & \multicolumn{2}{l|}{ Plant } \\
\cline { 2 - 12 } & WW $^{*}$ & $\mathbf{W S}^{* *}$ & WW & WS & WW & WS & WW & WS & WW & WS \\
\hline P0Fe0 & $2.00 \mathrm{c}^{2}$ & $1.24 \mathrm{c}$ & $1.72 \mathrm{c}$ & $1.35 \mathrm{c}$ & $0.95 \mathrm{~b}$ & $0.67 \mathrm{~b}$ & $0.05 \mathrm{c}$ & $0.02 \mathrm{c}$ & $4.72 \mathrm{~b}$ & $3.26 \mathrm{~d}$ \\
\hline $\mathrm{P} 100 \mathrm{Fe} 0$ & $2.84 \mathrm{a}$ & $1.76 \mathrm{~b}$ & $2.74 \mathrm{a}$ & $2.34 \mathrm{a}$ & $1.15 \mathrm{a}$ & $1.02 \mathrm{a}$ & $0.22 \mathrm{~b}$ & $0.10 \mathrm{~b}$ & $6.95 \mathrm{a}$ & $5.22 \mathrm{~b}$ \\
\hline $\mathrm{P} 0 \mathrm{Fe} 5$ & $1.90 \mathrm{c}$ & $1.35 \mathrm{c}$ & $2.10 \mathrm{~b}$ & $1.78 \mathrm{~b}$ & $0.74 \mathrm{~b}$ & $0.66 \mathrm{~b}$ & $0.05 \mathrm{c}$ & $0.03 \mathrm{c}$ & $4.75 \mathrm{~b}$ & $3.82 \mathrm{c}$ \\
\hline $\mathrm{P} 100 \mathrm{Fe} 5$ & $2.95 \mathrm{a}$ & $2.45 \mathrm{a}$ & $2.80 \mathrm{a}$ & $2.55 \mathrm{a}$ & $1.02 \mathrm{a}$ & $0.95 \mathrm{a}$ & $0.41 \mathrm{a}$ & $0.20 \mathrm{a}$ & $7.18 \mathrm{a}$ & $6.15 \mathrm{a}$ \\
\hline
\end{tabular}

$\mathrm{WW}^{*}$ well-watered $-70 \%$ WHC; $\mathrm{WS}^{* *}$ water stress $-35 \% \mathrm{WHC} ;{ }^{1}$ Mean of four replicates; ${ }^{2} \mathrm{Within}$ each column, same latter indicates no significant difference between treatments $(\mathrm{P} \leq 0.05)$.

The maximum positive effect of nutrients interaction was observed in normal moisture conditions. The process of nodulation was sensitive to both nutrient deficiencies as well as to water stress (Tables 1 and 2). The results of the present study showed that drought had significantly negative impact on nodules dry weight and there was cultivar effect. Licurici cultivar was more sensitive to water deficit than Zodiac one. Phosphorus sufficient supply considerably increased nodules growth in the two water regimes.

Table 2 Biomass production and partitioning of Licurici cultivar at low and adequate $\mathrm{P}$ and Fe supply grown under wellwatered and drought conditions, g plant -1 DW

\begin{tabular}{|l|c|c|c|c|c|c|c|c|c|c|}
\hline \multirow{2}{*}{ Treatments } & \multicolumn{2}{|c|}{ Leaves } & \multicolumn{2}{c|}{ Stem } & \multicolumn{2}{c|}{ Roots } & \multicolumn{2}{c|}{ Nodules } & \multicolumn{2}{c|}{ Plant } \\
\cline { 2 - 13 } & $\mathbf{W W}^{*}$ & $\mathbf{W S} * *$ & WW & WS & WW & WS & WW & WS & WW & WS \\
\hline P0Fe0 & $1.65 \mathrm{c}$ & $1.06 \mathrm{c}$ & $1.38 \mathrm{~d}$ & $1.26 \mathrm{~d}$ & $0.81 \mathrm{~b}$ & $0.59 \mathrm{~b}$ & $0.04 \mathrm{~b}$ & $0.02 \mathrm{~b}$ & $3.88 \mathrm{~d}$ & $2.93 \mathrm{~d}$ \\
\hline $\mathrm{P} 100 \mathrm{Fe} 0$ & $2.74 \mathrm{~b}$ & $1.70 \mathrm{~b}$ & $2.62 \mathrm{~b}$ & $2.49 \mathrm{~b}$ & $1.20 \mathrm{ab}$ & $0.93 \mathrm{a}$ & $0.22 \mathrm{a}$ & $0.14 \mathrm{a}$ & $6.78 \mathrm{~b}$ & $5.26 \mathrm{~b}$ \\
\hline P0Fe5 & $1.86 \mathrm{c}$ & $1.53 \mathrm{~b}$ & $1.62 \mathrm{c}$ & $1.62 \mathrm{c}$ & $0.81 \mathrm{a}$ & $0.55 \mathrm{~b}$ & $0.04 \mathrm{~b}$ & $0.03 \mathrm{~b}$ & $4.33 \mathrm{c}$ & $3.73 \mathrm{c}$ \\
\hline $\mathrm{P} 100 \mathrm{Fe} 5$ & $3.21 \mathrm{a}$ & $2.70 \mathrm{a}$ & $3.35 \mathrm{a}$ & $2.73 \mathrm{a}$ & $1.26 \mathrm{a}$ & $0.85 \mathrm{a}$ & $0.28 \mathrm{a}$ & $0.15 \mathrm{a}$ & $8.10 \mathrm{a}$ & $6.43 \mathrm{a}$ \\
\hline
\end{tabular}

WW* well-watered-70\% WHC; WS** water stress $-35 \%$ WHC; ${ }^{1}$ Mean of four replicates; ${ }^{2}$ Within each column, same latter indicates no significant difference between treatments $(\mathrm{P} \leq 0.05)$.

Adequate $\mathrm{P}$ and $\mathrm{Fe}$ nutrition reduced the negative impact of drought on nodulation performance. Analysis of experimental data revealed significant effects of $\mathrm{P}$ and Fe supply as well as cultivars effects on the concentration and content of $\mathrm{P}$ in leaves, roots and nodules (Figure 1, 2). Experimental results identified a strong positive effect (P $\leq 0.05$ ) between biomass production and $\mathrm{P}$ accumulation in soybeans cultivars. Water shortage decreased the capacity of $\mathrm{P}$ uptake by plants and its allocation to shoots. Application of $\mathrm{P}$ alone or in combination with Fe affected the pattern of nutrient allotted in plant parts. Phosphorus concentration in all the plant parts was markedly higher at nil Fe and it decreased with Fe application. Phosphorus concentrations were higher in leaves and nodules than in stems in both cultivars. Phosphorus concentration in plants of $\mathrm{cv}$. Zodiac increased evidently at adequate P supply under normal and deficit soil moisture (Figure 1A, B).

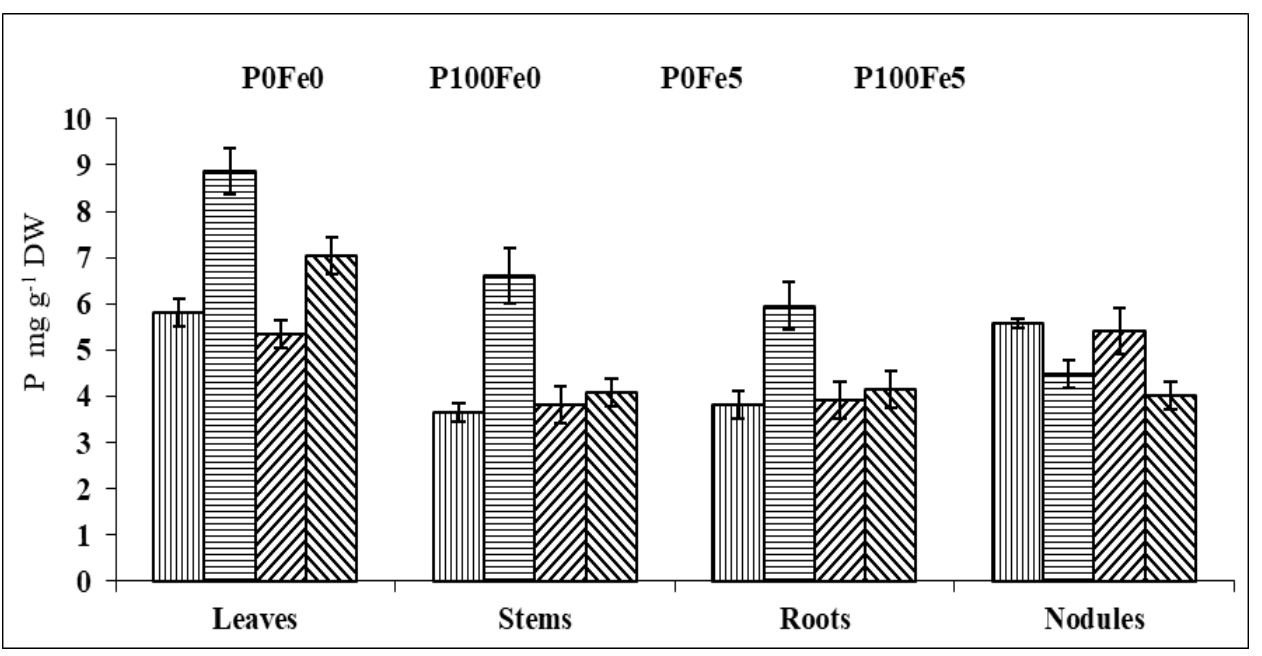




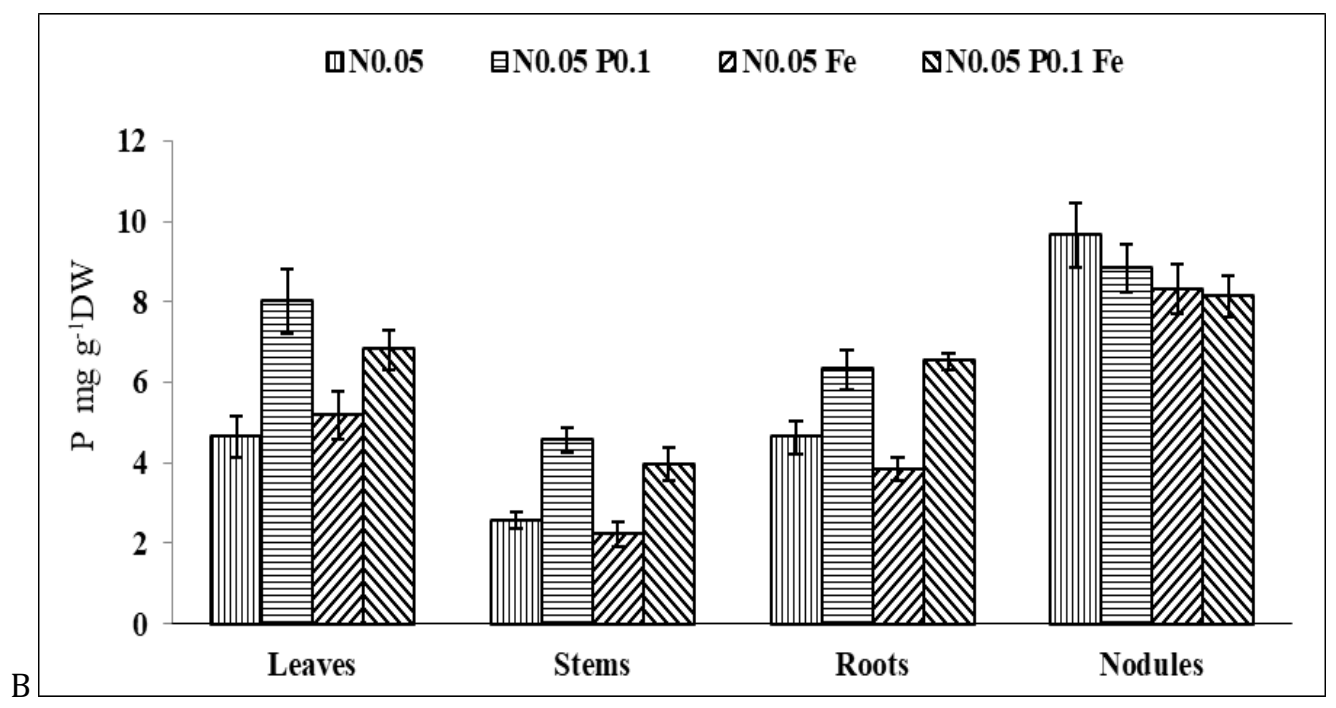

Figure $1 \mathrm{P}$ concentration (mg P g-1 DW) in plant parts of soybean cv. Zodiac at low and adequate nutrient levels of $\mathrm{P}$ and Fe under normal moisture (A) and drought conditions. Vertical bars represent the standard errors of means of three replicates, $\mathrm{P} \leq 0.05$.
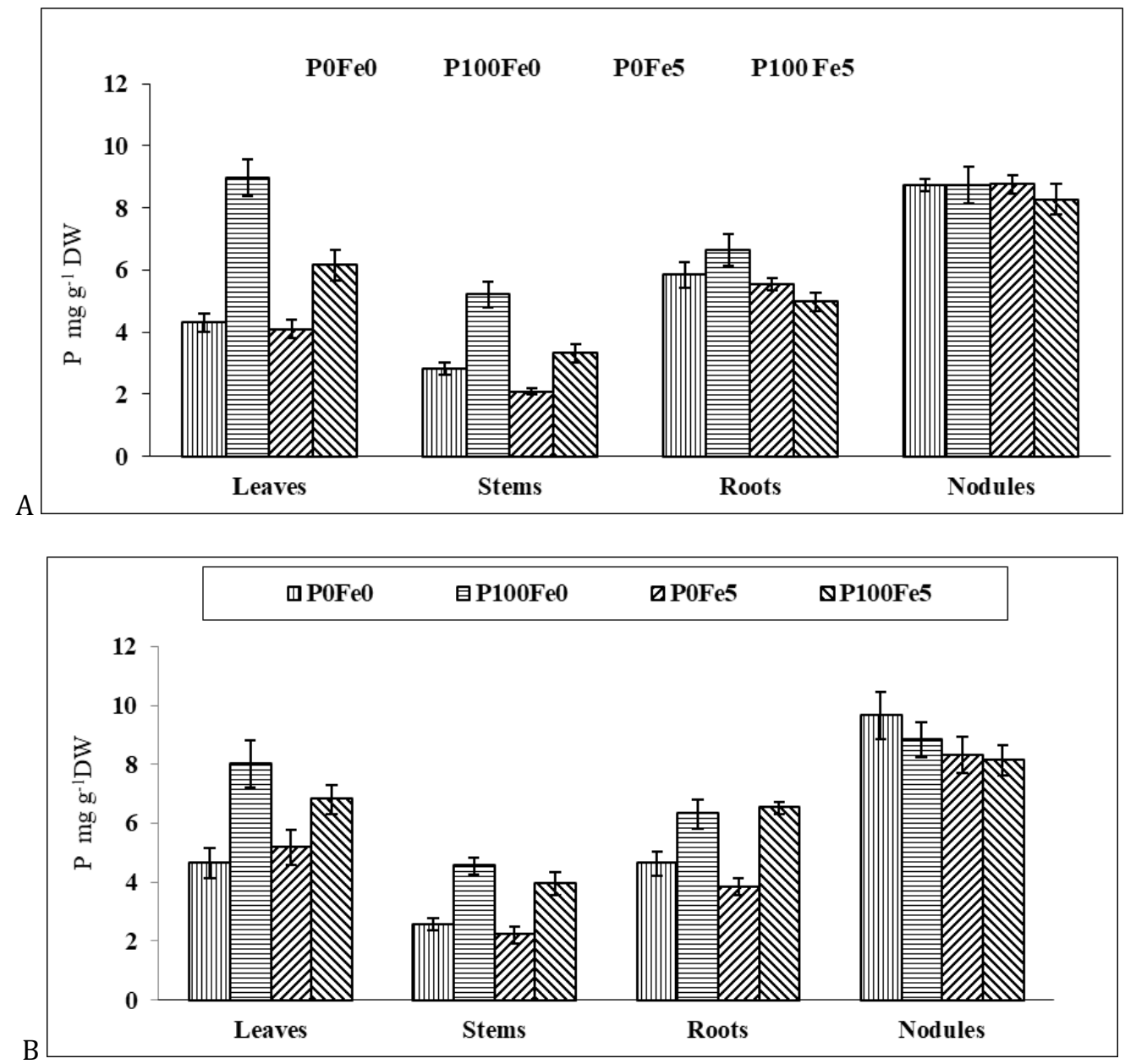

Figure $2 \mathrm{P}$ concentration $\left(\mathrm{mg} \mathrm{g}^{-1} \mathrm{DW}\right)$ in plant parts of soybean $\mathrm{cv}$. Licurici at low and adequate nutrient levels of $\mathrm{P}$ and Fe under normal (A) and low (B) soil moisture conditions. Vertical bars represent the standard errors of means of three replicates. $\mathrm{P} \leq 0.05$. 
Leaves had a more pronounced variation in $\mathrm{P}$ concentration than nodules. Drought caused an increase of nutrient concentration in plant parts. Phosphorus accumulation in vegetative organs (cv. Licurici) increased significantly $(\mathrm{P} \leq 0.05)$ in treatment with adequate $\mathrm{P}$ nutrition (Figure $2 \mathrm{~A})$. This trend was evidently observed in leaves irrespective of soil moisture (Figure 2A,B).

Iron concentrations in plant parts of soybean cultivars in relation to nutrient and water supply are presented in Table 3. No negative interaction between insufficient P supply and low Fe application on plant growth was observed, but a depressing effect of $\mathrm{P}$, applied at sufficient level on Fe concentration in plant tissues.

Table 3 Effect of phosphorus and iron supply on Fe concentrations ${ }^{1}\left(\mathrm{mg} \mathrm{kg}^{-1} \mathrm{DM}\right)$ in leaves and roots of Licurici and Zodiac cultivars in relation of soil moisture

\begin{tabular}{|l|c|c|c|c|c|c|c|c|}
\hline \multirow{3}{*}{ Treatments } & \multicolumn{4}{|c|}{ Licurici } & \multicolumn{4}{c|}{ Zodiac } \\
\cline { 2 - 10 } & \multicolumn{2}{|c|}{ Leaves } & \multicolumn{2}{c|}{ Roots } & \multicolumn{2}{c|}{ Leaves } & \multicolumn{3}{c|}{ Roots } \\
\cline { 2 - 10 } & WW $^{*}$ & WS** & WW & WS & WW & WS & WW & WS \\
\hline P0Fe0 & $250 b^{2}$ & $653 b$ & $1213 \mathrm{~b}$ & $1573 \mathrm{c}$ & $376 \mathrm{a}$ & $735 \mathrm{a}$ & $1675 \mathrm{a}$ & $1828 \mathrm{~b}$ \\
\hline P100Fe0 & $203 \mathrm{c}$ & $615 \mathrm{~b}$ & $1020 \mathrm{c}$ & $1535 \mathrm{c}$ & $329 \mathrm{~b}$ & $692 \mathrm{~b}$ & $1596 \mathrm{~b}$ & $1804 \mathrm{~b}$ \\
\hline P0Fe5 & $368 \mathrm{a}$ & $736 \mathrm{a}$ & $1377 \mathrm{a}$ & $1986 \mathrm{a}$ & $378 \mathrm{a}$ & $780 \mathrm{a}$ & $1662 \mathrm{a}$ & $2232 \mathrm{a}$ \\
\hline P100Fe5 & $243 \mathrm{~b}$ & $585 \mathrm{~b}$ & $1029 \mathrm{c}$ & $1670 \mathrm{~b}$ & $310 \mathrm{~b}$ & $786 \mathrm{a}$ & $1598 \mathrm{~b}$ & $2195 \mathrm{a}$ \\
\hline
\end{tabular}

applied at sufficient level on Fe concentration in plant tissues. Soybean cultivars varied significantly in Fe partitioning in leaves and roots irrespective of nutrients levels. Supplemental iron nutrition, without P application (P0Fe), increased significantly micronutrient uptake. Water deficit increased micronutrient concentrations in soybean cultivars, particularly in Zodiac. The proportion of total iron partitioned to leaves differed also markedly between cultivars. The higher value of iron concentrations in leaves and roots was denoted in treatment with adequate iron application and low P supply (P0Fe5).

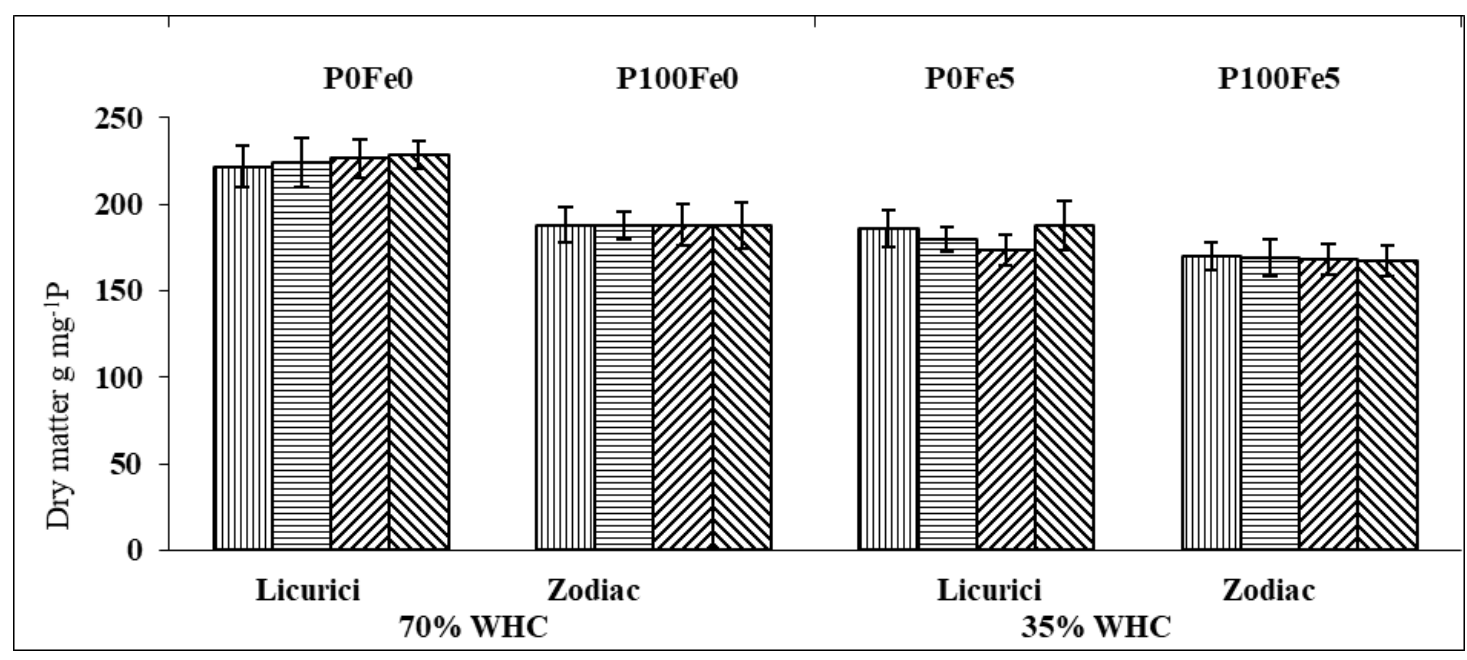

Figure 3 Phosphorus use efficiency (mg P g-1 DW) for dry matter production in Zodiac and Licurici under different nutrient and water supply. Bars show SE for three replicates. $\mathrm{P} \leq 0.05$.

Nutrient application and water regimes influenced the rate of PUE. Generally, the two cultivars had different values of PUE (Figure 3). Supplemental Fe nutrition in normal water conditions increased PUE and Licurici overcome Zodiac in this respect. 


\section{Discussion}

The dry matter accumulation is generally considered an integrate trait of plant ability to grow in different environments. Therefore, it is used as an essential criterion for evaluation of genotypes nutrient efficiencies [24]. Under conditions of low $\mathrm{P}$ and low Fe (P0Fe0), there were no symptoms of nutrients deficiencies in soybean plants. Plant dry matter production and partitioning were significant and positively correlated with nutrient supply.

Differences for partitioning of dry matter between aboveground plant parts and roots were more pronounced under Pdeficit treatment (P0). Moisture stress reduced substantially biomass production under insufficient $\mathrm{P}$ and Fe nutrition (Table 1 and 2). In both experiments, water stress decreased essentially leaves growth and the mass of nodules. There was not big difference between cultivars regarding nodules biomass under water deficit condition. Root growth was less influenced by water stress. However, reportedly the more drought tolerant chickpea genotypes had greater root systems than the less tolerant genotypes [25]. Among examined organs, nodules and leaves were the most affected by both environmental constraints $P$ deficit and drought. These results are somewhat consistent with those observed in Phaseolus vulgaris [5]. It was also revealed that water stress decreased leaf growth especially at low P and Fe supply. Phosphorus fertilization reduced drought effect on plant development and nodulation process. Probably, adequate $\mathrm{P}$ nutrition enhanced water conductivity as well as stimulated carbon metabolism. The same effects had reported in experiments with cotton [26]. Phosphorus insufficient supply decreased markedly plant growth in both cultivars but a cultivar effect was established. Our results are consistent with those described by Vadez et al. [5]. Iron application also increased plant growth but at low extent than $\mathrm{P}$ did. These results are contrary of experimental data in pigeon pea [27]. A positive interaction between $\mathrm{P}$ and $\mathrm{Fe}$ on plant biomass production was observed regardless of soil moisture conditions. The magnitude of the effect depended on genetic background of soybean cultivar. Insufficient nutrient supply reduced DM accumulation, especially in Zodiac. It should be noted that P supplemental nutrition alleviated leaf development in drought conditions as well as nutrients accumulation. Similar results were observed in moth bean genotypes in the experiments conducted by Garg et al. [6]. Likewise, adequate P nutrition significantly increased nodulation performance especially in well-watered plants. As a result of nodules growth plant development increased which in turn led to vigorous canopy of the plants.

Development of root system is a key factor estimating the effects of many environmental stresses because of its essential role in the soil-plant interaction [4]. Roots growth responded to P supply and water conditions. Experimental data suggest that soybean plants supplied with sufficient $\mathrm{P}$ have greater root system that allows the plants to extract more nutrients from larger soil volume. Therefore, adequate nutrition of $\mathrm{P}$ and Fe provided better plant performance due to increased capacity of plants to allocate nutrients to the leaves and thereby, perhaps, exerted feedback regulation on root and nodules activities.

The importance of Fe in legume comes from its role in several metabolic pathways. Iron is crucial for biological nitrogen fixation of legumes [28]. Our previous experiments showed that Fe sufficient supply affects nodules growth and their $\mathrm{N}_{2}$ fixation capability [14]. The results of present study are in agreement with other studies conducted on chickpea [29], lentil [30] and lupine [17] showing that Fe deficiency decreases significantly initiation and development of nodules and therefore affects plant development. In addition, Moreau et al. [31] showed that nodulated plants cultivated on $\mathrm{N}$-free medium need more Fe than those that without nodules cultivated on medium containing mineral nitrogen. Therefore, the interaction between iron nutrition and inoculated plant growth suggests that symbiotic $\mathrm{N}_{2}$ fixation has a greater requirement than host plant growth and the effect of iron on the symbiosis is direct [32]. Drought did not change much the pattern of iron influence on partitioning of dry matter within plants. For instance, leaves growth did not change significantly in relation to Fe supply under drought. However, in well-watered plants iron enhanced leaves growth in Licurici. The influence of adequate iron supply was detected on nodules of plants grown under normal moisture conditions. The same positive effect of iron supply was observed on peanut nodules growth [33]. When soil moisture level decreased from $70 \%$ WHC to $35 \%$ WHC the plants that received sufficient Fe was less affected by drought compared to plants with low Fe supply. The results of Krouma et al. [34] showed that the relative tolerance of cultivar common bean ARA14 to iron deficiency is linked with a higher leghemoglobin accumulation, which ensures a better control of $\mathrm{O}_{2}$ diffusion inside the nodules, and a better iron nutrition.

The pattern of nutrients partitioning within soybean plants was affected by both nutrient supply and water regime. There was interaction effect between $\mathrm{P}$ and Fe on nutrient partitioning in soybean. Insufficient iron supply increased $\mathrm{P}$ concentration in leaves. A higher proportion of $\mathrm{P}$ allocated to shoots under insufficient Fe nutrition may be the result of an interruption of the negative feedback of $P$ uptake by reducing the translocation of $P$ from shoots to roots [11]. The experimental results showed that iron application did not decrease the total $\mathrm{P}$ contents in whole plants. The same results were obtained in experiments with lupine [35]. These researchers demonstrated that addition of Fe-EDDHA increased concentrations and accumulation of $\mathrm{B}, \mathrm{Zn}, \mathrm{Cu}$ and $\mathrm{P}$ in Lupinus pilosus. Data of this study indicated that the 
nodules seem to have a priority over the other plant parts when P supply is limited. This is because the sink strength of nodules for $\mathrm{P}$ is higher due to the high demand for ATP by nitrogenase compared to the plant cells [13]. Thus, our results demonstrated that the rate of $\mathrm{P}$ absorption is an essential factor to increase DM production. In the present experiment Fe deficiency was not evident under low Fe supply, and adequate Fe supply [13] a marginal influence on tissue P concentrations in both cultivars. It was established that adequate Fe supply increased Fe concentration in roots, especially in Zodiac cultivar. High root Fe concentrations is a typically phenomenon which was found by several studies [3]. There was established correlation $(\mathrm{P} \leq 05)$ between DM production and iron concentration in leaves. The correlation between biomass production and Fe nutrition might be explained by the stimulus effect of Fe on nodule growth providing plants with nitrogen. Similar effect has been confirmed in lupine [18]. This could also probably be the case of soybean. On the other hand, iron is essential for photosynthesis, synthesis of nitrogen compounds and other protein enzymes increasing legume performance [36]. In both cultivars, it was revealed a trend of a decrease in Fe concentration in plant parts with increasing $\mathrm{P}$ in the growth medium. This may be attributed to growth dilution effect, which is evident from the difference in DM production. In addition, in those conditions probably there was an antagonistic effect between macronutrient and micronutrient [12]. Examination of Fe partitioning within soybeans showed that Fe concentration in leaves in water stress treatment increased in both cultivars. Experimental showed that the roots seem to have a priority over the leaves irrespective of treatments.

Phosphorus use efficiency is important physiological traits in selection of genotypes and providing basis for low nutrient tolerance in crops. Phosphorus use efficiency, the integrated physiological parameter, is strong related to plant biomass production and phosphorus uptake. Many investigators reported a positive influence of PUE on plant performance of different crops at the reproductive and vegetative stages at low and adequate P levels [37]. High correlation values observed between PUE and biomass production across the treatments ( $r>0.82)$. Supplemental Fe nutrition increased the rate of PUE in cultivars under water deficit and normal water environments. In the other investigation a positive effect of phosphorus fertilizer on PUE in common bean [5] was revealed. Gunawardena et al. [38] have shown a significant difference in PUE of soybeans cultivars under normal water conditions. It is necessary to be noted that the differences among soybean cultivars grown under water stress were observed. Licurici had higher rates of PUE than Zodiac, under well-watered conditions. Improvement of tolerance of this cultivar to water shortage is related to a greater PUE that is confirmed by better growth of roots and leaves. The results indicated that appropriate resources (water and P) could contribute to higher carbon and nitrogen assimilation, leading to optimal growth and higher nutrient efficiency. Hence, there was a positive interactive effect of $\mathrm{P}$ and Fe on PUE of cultivars. Overall investigation results demonstrated that the interactive effects of $P$ and Fe on partitioning of dry mass and nutrients within plants under different moisture conditions are related by genetic background for soybean cultivars.

\section{Conclusion}

The comparison of growth responses to $\mathrm{P}$ and Fe supply in the two nutrient media suggests that there was a cultivar effect on dry mass partitioning and nutrient allocation in plants. Cultivar Licurici was efficient in both $\mathrm{P}$ contents and PUE and has potential for tolerating water stress environment because of efficient utilization of nutrients for biomass production. Hence, adequate P and Fe supply would be recommended to maintain growth, enhanced nutrient status, and partially alleviate drought effect on performance of soybeans in stressed environments. Further investigations targeting the interaction of $\mathrm{P}$ and Fe on yields and nutritional quality of grains could be new foci for field investigations.

\section{Compliance with ethical standards}

\section{Acknowledgments}

The Supreme Council of Sciences and Technology of the Moldavian Academy of Sciences supported the research. An unknown reviewer is thanked for helpful comments to the manuscript.

\section{Disclosure of conflict of interest}

The authors declare that there is no conflict of interest.

\section{References}

[1] Boyer JS. Plant productivity and environment. Science. 1982; 218: 443-448.

[2] Garg BK. Nutrient uptake and management under drought: nutrient-moisture interaction. Current in Agronomy. 2003; 27: 1-8. 
[3] Dasa F, Abera T. Factors affecting iron absorption and mitigation mechanisms: A review. Internal Journal of Agricultural Science and Food Technology. 2018; 4(1): 24-30.

[4] Vance CP, Claudia US, Deborah A. Phosphorus acquisition and use: critical adaptations by plants for securing a nonrenewable resource. New Phytologist. 2003; 157: 423-447.

[5] Vadez V, Lasso JH, Beck DP, Drevon JJ. Variability of N2-fixation in common bean (Phaseolus vulgaris L.) under P deficiency is related to P use efficiency. Euphytica. 1999; 106: 231-242.

[6] Garg BK, Burman U, Kathju S. The influence of phosphorus nutrition on the physiological response of moth bean genotypes to drought. Journal of Plant Nutrition \& Soil Sciences. 2004; 167: 503-508.

[7] Israel DW. Investigation of the role of phosphorus in symbiotic dinitrogen fixation. Plant Physiol.1987; 84: 835840.

[8] Gentili F, Huss-Danell K. Phosphorus modifies the effects phosphorus and nitrogen on nodulation in split-root systems of Hippophae rhamnoides. New Phytologist. 2002; 153: 53-61.

[9] Israel DW, Rufty TW. Influence of phosphorus nutrition on phosphorus and nitrogen utilization efficiencies and associated physiological responses in soybean. Crop Sciences. 1988; 6: 954-960.

[10] Rufty TW, Israel DW, Volk RJ, Qiu J, Sa T. Phosphate regulation of nitrate assimilation in soybean. Journal of Expimental Botany. 1993; 44: 879-891.

[11] Xie X, Hu W, Fan X, Chen H, Tang M. Interactions between phosphorus, zinc, and iron homeostasis in nonmycorrhizal and mycorrhizal plants. Frontier in Plant Sciences. 2019; 10: 1172.

[12] Zhao D, Li X, Zhao L, Li L, Zhang Y, Zhang Z, Liu L, Xu H. Zhao W, Wu T, Siddique KHM. Comparison of zinc and iron uptake among diverse wheat germplasm at two phosphorus levels. Cereal Research Communications. 2020; 48: 441-448.

[13] Jakobsen I. The role of phosphorus in nitrogen fixation by young pea plants (Pissium sativum). Physiology Plantarum. 1985; 64: 190-196.

[14] Rotaru V, Sinclair RT. Interactive influence of phosphorus and iron on nitrogen fixation by soybean. Environmental \& Experimental Botany. 2009; 66: 94-99.

[15] Tóth B, van Biljon A, Labuschagne M. Effects of low nitrogen and low phosphorus stress on iron, zinc and phytic acid content in two spring bread wheat cultivars. Preprints 2018070498. 2018.

[16] Shahbazi F, Nematollahi A. Influences of phosphorus and foliar iron fertilization rate on the quality parameters of whole wheat grain. Food Science \& Nutrition. 2019; 7(2): 442-448.

[17] Datin CL, Westerman RL. Effect of phosphorus and iron on grain sorghum. Journal of Plant Nutrition. 1982; 5: 703-714.

[18] Tang C, Robson AD, Dilworth MJ. The role of iron in nodulation and nitrogen fixation in Lupinus angustifolis L. New Phytologist. 1990; 114(2): 173-182.

[19] Payne WA, Drew MC, Hossner LR, Lascano RJ, Onken AB, Wendt CW. Soil phosphorus availability and pearl millet water-use efficiency. Crop Sciences. 1992; 32: 1010-1015.

[20] Samarah N, Mullen R, Cianzio S. Size distribution and mineral nutrients of soybean seeds in response to drought stress. Journal of Plant Nutrition. 2004; 27: 815-835.

[21] Jin J, Wang G, Liu X, Pan X, Herbert S. Phosphorus application affects the soybean root response to water deficit at the initial flowering and full pod stages. Soil Sciences \& Plant Nutrition. 2005; 51: 953-960.

[22] Singh DK, Sale PWG. Growth and potential conductivity of white clover roots in dry soil with increasing phosphorus supply and defoliation frequency. Agronomy Journal. 2000; 92: 868-874.

[23] Murphy J, Riley J. A modified single solution method for the determination of phosphate in natural waters. Analytical Chemistry Acta. 1962; 27: 31-36.

[24] Fageria NK, Baligar VC, Clark RB. Micronutrients in crop production. Advances in Agronomy. 2002; 77: $185-267$.

[25] Ali MD, Krishnamurty I, Saxena NP, Rupela OP, Kumar J, Johansen C. Scope for genetic manipulation of mineral acquisition in chickpea. Plant \& Soil. 2002; 245: 123-134. 
[26] Radin JW. Stomatal responses to water stress and to abscisic acid in phosphorus-deficient cotton plants. Plant Physiology. 1984; 176: 392-394.

[27] Reddy DS, Gopal R, Polasa H. Iron dependent ureides and allantionase synthesis in pigeon pea. Journal of Plant Nutrition. 1995; 18: 937-947.

[28] Thoiron S, Pascal N, Briat JF. Impact of iron deficiency and iron re-supply during the early stages of vegetative development in maize (Zea mays L.,). Plant Cell \& Environment. 1997; 20: 1051-1060.

[29] Rai R, Singh SN, Prassad V. Effect of presumed-amended pyrite on symbiotic N2-fixation, active iron contents of nodules, grain yield and quality of chickpea (Cicer arietinum L.) lines in calcareous soil. Journal of Plant Nutrition. 1982; 5: 905-913.

[30] Rai R, Prassad V, Choudhry SK, Sinha NP. Iron nutrition and symbiotic N2 fixation of lentil (Lens culinaris) lines in calcareous soil. Journal of Plant Nutrition. 1984; 7: 399-405.

[31] Moreau S, Meyer JM, Pupo A. Uptake of iron by symbiotic and bacteroids from soybean nodules. FEBS Letters. 1995; 361: 225-228.

[32] Robson AD. Mineral nutrition. In Nitrogen fixation v.3, Ed W.J. Broughton. 1983; 36-55.

[33] Singh DK, Sahu MP. Effects of phosphate carriers, iron, and indoleacetic acid on iron nutrition and productivity of peanut on a calcareous soil. Journal of Plant Nutrition. 1993; 16: 1847-1855.

[34] Krouma A, Karim BH, Chedly A. Symbiotic response of common bean (Phaseolus vulgaris L.) to iron deficiency. Acta Physiology Plantarum. 2008; 30: 27-34.

[35] Brand JD, Tang C, Graham RD. The effect of soil moisture on the tolerance of Lupinus pilosus genotypes to a calcareous soil. Plant \& Soil. 2000; 219: 41-47.

[36] Wiersma JV. Iron acquisition of three soybean varieties grown at five seeding densities and five rates of FeEDDHA. Agronomy Journal. 2007; 99: 1018-1028.

[37] Baligar VC, Fageria NK, He ZL. Nutrient use efficiency in plants. Communication in Soil Science and Plant Analyzes. 2001; 32: 921-950.

[38] Gunawardena SFN, Danso SKA, Zapata F. Phosphorus requirements and sources of nitrogen in three soybean (Glycine max.) genotypes, Bragg, nts 382 and Chippewa. Plant \& Soil. 1993; 151: 1-9. 